\section{Diagnosing Achilles tendinopathy is like delicious spaghetti carbonara: it is all about key ingredients, but not all chefs use the same recipe}

\author{
Robert-Jan de Vos (D) , 1 Arco C van der Vlist (D) ,' Marinus Winters \\ Florus van der Giesen, ${ }^{3}$ Adam Weir ${ }^{1}$
}

Achilles tendinopathy is the term used to describe the clinical entity of localised Achilles tendon pain that is associated with load-bearing activities. Achilles tendinopathy as a term was agreed on the 2018 International Scientific Tendinopathy Symposium Consensus (ICON) statement-which followed an expert meeting in Groningen (the Netherlands). ${ }^{1}$ Having uniform terminology is important for many reasons. But a clinical term is not the same as a diagnosis with clear diagnostic criteria. Clear diagnostic criteria help patients understand their problem, guide treatment and determine prognosis. Naming a medical condition can be likened to naming a recipe, but the exact ingredients used can differ between chefs. In this editorial, we discuss the diagnostic challenges, where 'top chefs' disagree

'Department of Orthopaedics and Sports Medicine, Erasmus Medical Center, Rotterdam, Zuid-Holland, The Netherlands

${ }^{2}$ Research Unit for General Practice in Aalborg, Department of Clinical Medicine, Aalborg Universitet Det Sundhedsvidenskabelige Fakultet, Aalborg, Denmark

${ }^{3}$ Department of Rheumatology, Leiden University Medical Center, Leiden, Zuid-Holland, The Netherlands

Correspondence to Dr Robert-Jan de Vos, Department of Orthopaedics and Sports Medicine, Erasmus Medical Center, Rotterdam 3000 CA, ZuidHolland, The Netherlands; r.devos@erasmusmc.nl which ingredients are present in midportion Achilles tendinopathy.

\section{THE PARADIGM SHIFT IN DIAGNOSING INJURIES IN SPORTS MEDICINE}

Many medical diagnostic tests are often validated by comparing them to a gold standard (eg, imaging, surgical or histological findings). Most sports injuries and long-standing musculoskeletal pain conditions have unclear pathogenesis and lack clear gold standards (consider patellofemoral pain). When imaging was added to the clinical diagnostic criteria in patients with patellofemoral pain it added no value. ${ }^{2}$ The classic tissue-based diagnosis paradigm has been increasingly abandoned. A paradigm shift towards using history and clinical examination as the cornerstones in the diagnostic process has occurred. Could this work in Achilles tendinopathy?

\section{CLINICAL DIAGNOSTIC CRITERIA: WHICH INGREDIENTS ARE NEEDED FOR ACHILLES TENDINOPATHY?}

Patient history is incontrovertibly an essential ingredient to diagnose Achilles tendinopathy — patients must have Achilles tendon pain, which worsens on loading. ${ }^{1}$ Also, patients can point to whether their pain is localised to the Achilles tendon. On examination, physicians can assess localised tendon thickening with tenderness (pain on palpation). These three clinical findings are simple and can be assessed reliably ${ }^{3}$ - but are all three of them essential ingredients to diagnose Achilles tendinopathy?

\section{WHAT DO TOP CHEFS SAY?}

Let's examine which diagnostic criteria expert researchers use. Do their Achilles tendinopathy cookbooks all use the same ingredients? Our recent review with network meta-analysis on treatments for mid-portion Achilles tendinopathy ${ }^{4}$ extracted diagnostic criteria from 25 randomised controlled trials. Localised Achilles tenderness, localised tendon thickening and pain associated with loadbearing activities were the most commonly used ingredients (figure 1). When all three clinical diagnostic elements are present, the clinical diagnosis seems straightforward-just like if one is presented with a traditional carbonara. But there are less straightforward clinical cases, like when the tendon is painful but there is no thickening. This is where it becomes a challenge to define the point at which the condition is deemed to be present. There is spaghetti, egg and bacon, but no parmesan-is it still carbonara? It may well be that there are variations within the recipe (ie, subclassifications) but it would be great if chefs could agree on this.

\section{SHOULD IMAGING BE PART OF THE RECIPE?}

Imaging might be useful, especially in challenging cases where not all clinical diagnostic criteria are present. It can depict characteristic changes for tendinopathy: increased tendon thickness, abnormal tendon structure and increased vascularity. A major drawback of imaging is that 'abnormal' findings (also referred to as 'morphological changes') are present in $25 \%$ of asymptomatic Achilles 


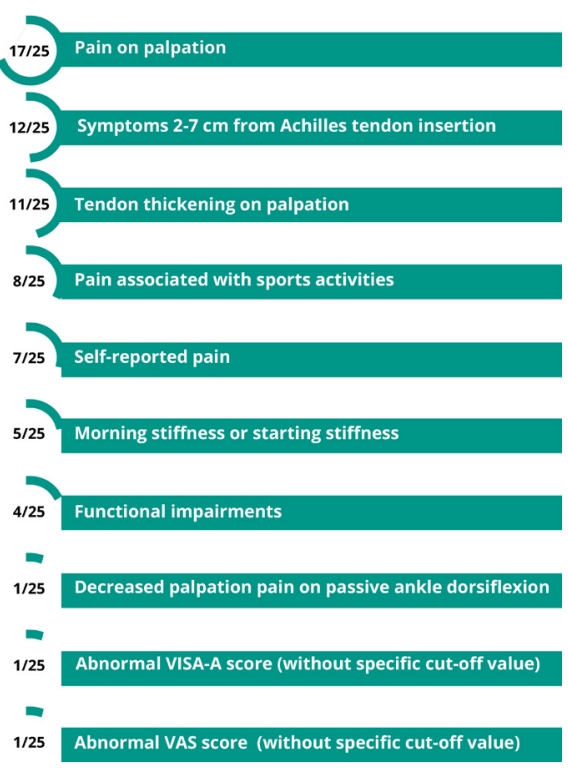

Figure 1 Extracted criteria used for the diagnosis in the randomised trials for midportion Achilles tendinopathy $(n=25)$. The displayed signs and symptoms are located to the Achilles tendon mid-portion or are a result of pain in this area. VISA-A; Victorian Institute of Sport Assessment-Achilles. VAS; Visual Analogue Scale.

tendons. ${ }^{5}$ A similar problem is present in other musculoskeletal disorders, such as osteoarthritis. $^{6}$

How do expert chefs feel about imaging? The majority $(74 \%)$ of the ICON participants felt that imaging was not an essential ingredient for diagnosing Achilles tendinopathy. ${ }^{1}$ Yet more than half $(55 \%)$ of the randomised studies we reviewed ${ }^{4}$ used imaging in the diagnostic process. It is clear that top chefs do not all agree on the need for imaging!

\section{IS A PATHOLOGICAL TENDON A VITAL INGREDIENT TO DIAGNOSE ACHILLES TENDINOPATHY?}

A recipe where the patient has localised Achilles tenderness and a normal imaging appearance is another challenging case. Is that Achilles tendinopathy? Cook and Purdam's proposed continuum model of pathology proposes a potential sequence of changes. ${ }^{7}$ Increased tendon cell proliferation and glycosaminoglycans with wellarranged tendon fibres are the features of early reactive tendinopathy. These findings cannot be detected using conventional ultrasound or MRI. While the presence of pathological changes in that situation cannot be confirmed with current method, that phenomenon (localised tenderness with 'normal' imaging) may be a subcategory of Achilles tendinopathy (early stage tendinopathy_preimaging). This opens the discussion whether we should consider tendinopathy as a clinical entity (like patellofemoral pain) or as a continuum with specific progressive pathology (like osteoarthritis, which uses the Kellgren and Lawrence Scale to classify the radiological severity of the disease). Should we distinguish different subclassifications of Achilles tendinopathy?

\section{CAN WE AGREE ON THE EXACT RECIPE(S) FOR ACHILLES TENDINOPATHY?}

It is hard to define the exact ingredients needed to diagnose Achilles tendinopathy. How can we improve our diagnostic recipe(s)? The ICON meetings, where lots of top chefs attend, could be an appropriate platform to initiate a new widely supported agreement on diagnostic criteria for Achilles tendinopathy. Uniform diagnostic recipes on when to diagnose Achilles tendinopathy would be a great start. ${ }^{8}$ Identifying possible subclassifications, based on certain diagnostic ingredients, has several possible advantages: improving tailored individual treatments or better inform us a patient's prognosis. ${ }^{9}$

Twitter Robert-Jan de Vos @ri_devos, Arco C van der Vlist @ArcoVlist and Marinus Winters @marinuswinters

Acknowledgements We would like to extend our gratitude to WM Bramer, research librarian at Erasmus MC, for his help with developing a sensitive search strategy.

Contributors R-JdV made the first draft of the manuscript. MW, FvdG, AW and ACvdV revised the manuscript.

Funding The authors have not declared a specific grant for this research from any funding agency in the public, commercial or not-for-profit sectors.

Competing interests None declared.

Patient consent for publication Not required.

Provenance and peer review Not commissioned; externally peer reviewed.

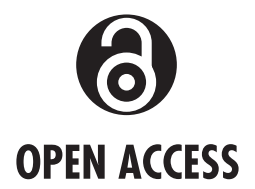

Open access This is an open access article distributed in accordance with the Creative Commons Attribution Non Commercial (CC BY-NC 4.0) license, which permits others to distribute, remix, adapt, build upon this work non-commercially, and license their derivative works on different terms, provided the original work is properly cited, appropriate credit is given, any changes made indicated, and the use is non-commercial. See: http://creativecommons.org/ licenses/by-nc/4.0/.

(C) Author(s) (or their employer(s)) 2021. Re-use permitted under CC BY-NC. No commercial re-use. See rights and permissions. Published by BMJ.

\section{Check for updates}

To cite de Vos R-J, van der Vlist AC, Winters M, et al. Br J Sports Med 2021;55:243-248.

Accepted 30 September 2020 Published Online First 14 October 2020

Br J Sports Med 2021;55:243-248.

doi:10.1136/bjsports-2020-102863

\section{ORCID iDs}

Robert-Jan de Vos http://orcid.org/0000-0003-03720188

Arco C van der Vlist http://orcid.org/0000-0003-42383540

Marinus Winters http://orcid.org/0000-0001-57427441

\section{REFERENCES}

1 Scott A, Squier K, Alfredson H, et al. Icon 2019: international scientific tendinopathy symposium consensus: clinical terminology. Br J Sports Med 2020;54:260-2.

2 van der Heijden RA, de Kanter JLM, Bierma-Zeinstra SMA, et al. Structural abnormalities on magnetic resonance imaging in patients with Patellofemoral pain: a cross-sectional case-control study. Am J Sports Med 2016:44:2339-46.

3 Hutchison A-M, Evans R, Bodger 0, et al. What is the best clinical test for Achilles tendinopathy? Foot Ankle Surg 2013;19:112-7.

4 van der Vlist AC, Winters M, Weir A, et al. Which treatment is most effective for patients with Achilles tendinopathy? A living systematic review with network meta-analysis of 29 randomised controlled trials. $\mathrm{Br} \mathrm{J}$ Sports Med 2020. doi:10.1136/bjsports-2019-101872. [Epub ahead of print: 10 Jun 2020].

5 McAuliffe S, McCreesh K, Culloty F, et al. Can ultrasound imaging predict the development of Achilles and Patellar tendinopathy? A systematic review and meta-analysis. Br J Sports Med 2016;50:1516-23.

6 de Vos R-J, van Osch GJ, Bierma-Zeinstra SMA, et al. Tendinopathy and osteoarthritis: a chance to kill two birds with one stone. Br J Sports Med 2016;50:1164-5.

7 Cook JL, Purdam CR. Is tendon pathology a continuum? A pathology model to explain the clinical presentation of load-induced tendinopathy. Br J Sports Med 2009;43:409-16

8 Rudwaleit $M$, van der Heijde $D$, Landewé $R$, et al. The development of assessment of spondyloarthritis International Society classification criteria for axial spondyloarthritis (Part II): validation and final selection. Ann Rheum Dis 2009:68:777-83.

9 Croft P, Altman DG, Deeks JJ, et al. The science of clinical practice: disease diagnosis or patient prognosis? Evidence about "what is likely to happen" should shape clinical practice. BMC Med 2015;13:20. 